\title{
DIAGNÓSTICO DA GESTÃO DE DUAS MICROEMPRESAS FAMILIARES QUE ATUAM NO RAMO DE COMÉRCIO DE ALIMENTO PARA ANIMAIS NA CIDADE DE VARGINHA- MG
}

Fabiane Fidelis Querino ${ }^{1}$

Leandro Rivelli Teixeira Nogueira ${ }^{2}$

Maria Aparecida Curi ${ }^{2}$

Fernanda Teixeira Franco Ribeiro ${ }^{1}$

\footnotetext{
${ }^{1}$ Universidade Federal de Lavras

${ }^{2}$ Universidade Federal de Alfenas
} 


\section{DIAGNÓSTICO DA GESTÃO DE DUAS MICROEMPRESAS FAMILIARES QUE ATUAM NO RAMO DE COMÉRCIO DE ALIMENTO PARA ANIMAIS NA CIDADE DE VARGINHA-MG}

Resumo: O presente trabalho tem como objetivo fazer um diagnóstico da gestão de duas microempresas familiares que atuam no comércio de alimentos para animais na cidade de Varginha-MG, buscando identificar como estes empreendedores utilizam as ferramentas de gestão no processo de tomada de decisão. Foi feita uma análise descritiva, que através da realização de uma entrevista semiestruturada nas empresas selecionadas foi possível identificar que quando os empreendedores utilizam as ferramentas de gestão, acarreta em um conhecimento da real situação financeira enfrentada pela empresa, permitindo assim a criação de metas e estratégias para a melhor atuação desta no mercado. Se tratando de empresas familiares a falta de organização entre empresa e família acaba levando as empresas estarem em situações críticas diante do mercado.

Palavras-chave: Microempresa. Empresa familiar. Ferramentas de gestão. Comércio de alimentos de animais.

\section{$1 \quad$ Introdução}

A atividade comercial é uma prática utilizada desde a antiguidade. Segundo Mankiw (2014), o comércio é uma prática que beneficia a todos e cada um irá se especializar na atividade no qual possui a maior vantagem comparativa. Na crise financeira iniciada nos Estados Unidos em meados de 2007, devido ao aumento da inadimplência e a desvalorização dos imóveis e ativos financeiros associados as hipotecas americanas de alto risco, com a desaceleração da econômica, o comércio assim como as outras atividades da economia, vem sofrendo quedas de vendas. (Cintra; Farhi, 2008).

Por isso é importante que os empreendedores façam uma análise financeira de seu empreendimento para verificar como está a saúde financeira do mesmo. Através da análise financeira, os empreendedores irão ter o conhecimento da real situação vivenciada pela empresa. Quais as principais dificuldades enfrentadas e quais os meios para solucioná-las. Além disso, essa análise mostrara aos empreendedores o destino de todos os recursos financeiros que a empresa obteve e criar objetivos e metas futuras para o estabelecimento.

Dessa forma, o presente trabalho tem como objetivo central fazer um diagnóstico da gestão de duas microempresas familiares que atuam no comércio de ração animal, buscando identificar como os empreendedores utilizam as ferramentas de gestão no processo de tomada de decisão. Essa pesquisa se justifica devido ao aumento significativo desse segmento na cidade de Varginha- MG. Segundo as informações do portal Empresômetro desenvolvido pelo Instituto Brasileiro do Planejamento e Tributação-IBPT- (2017), houve um aumento de 25,81\% no número de estabelecimentos entre os anos de 2015 a 2017.

Desde modo, o estudo pretende contribuir com a literatura de duas maneiras. A primeira é reforçar a importância dos gestores das micro e pequenas empresas de fazerem as análises 
financeiras através dos indicadores para poderem assim ter um maior controle sobre a saúde financeira dos estabelecimentos, visto que este segmento é responsável por $60 \%$ dos empregos formais e 20\% do PIB do país (SILVA, SANTOS e SILVA, 2016). E o segundo é analisar de que forma a utilização dessas ferramentas podem gerar benefícios para o empreendimento.

A fim de alcançar os objetivos do trabalho serão apresentadas as classificações das empresas, o conceito de empresa familiar e seus tipos, funções das empresas, ferramentas de gestão, o princípio da entidade, custo de agência, artigos com temas relacionados e posteriormente a metodologia, os resultados e discussões e por fim as considerações finais.

\title{
2
}

Referencial Teórico

\section{Microempresa e Empresa de Pequeno Porte}

De acordo com a lei complementar $n^{\circ} 155$, de 27 de outubro de 2016:

\begin{abstract}
Para os efeitos desta Lei Complementar, consideram-se microempresas ou empresas de pequeno porte, a sociedade empresária, a sociedade simples, a empresa individual de responsabilidade limitada e o empresário a que se refere o art. 966 da Lei no 10.406, de 10 de janeiro de 2002 (Código Civil), devidamente registrados no Registro de Empresas Mercantis ou no Registro Civil de Pessoas Jurídicas, conforme o caso, desde que: I - no caso da microempresa, aufira, em cada ano-calendário, receita bruta igual ou inferior a $\mathrm{R} \$ 360.000,00$ (trezentos e sessenta mil reais); e II - no caso de empresa de pequeno porte, aufira, em cada ano-calendário, receita bruta superior a $\mathrm{R} \$$ $360.000,00$ (trezentos e sessenta mil reais) e igual ou inferior a $\mathrm{R} \$ 4.800 .000,00$ (quatro milhões e oitocentos mil reais). (BRASIL,2016).
\end{abstract}

De acordo com SEBRAE (2016), no Brasil existem 6,4 milhões de empresas, desse total $99 \%$ são micro e pequenas empresas, sendo que, as microempresas são responsáveis por $52 \%$ dos empregos com carteira assinada no país.

\subsection{Ferramentas de Gestão}

As ferramentas de gestão apresentadas a seguir são relevantes para o acompanhamento da saúde financeira de uma microempresa, contribuindo assim, para um processo de tomada de decisão mais profissionalizado.

A) CONTROLE DIÁRIO DE CAIXA: É a apuração diária das entradas e saídas de caixa que resultaram no final do dia no saldo que o empreendedor possui disponível em caixa, Reinert (2007). Esta ferramenta é importante para identificar a origem dos pagamentos, recebimentos e depósitos bancários e fornecer informações para a formulação do fluxo de caixa, de acordo com Assaf Neto e Lima (2009).

B) CONTROLE DIÁRIO DAS VENDAS: Nogueira e Assis (2014) afirmam que este índice tem como finalidades acompanhar as vendas diárias realizadas pelo estabelecimento, para no final do mês ser apurado a quantidade de mercadorias vendidas e observar se o número está sendo compatível com a meta do estabelecimento. 
C) CONTROLE DE CONTAS A PAGAR: Essa ferramenta possibilita ao gestor uma melhor visualização das obrigações que ele possui com terceiros durante o mês, Reinert (2007), D) CONTROLE MENSAL DE CONTAS A RECEBER: Segundo Nogueira e Assis (2014), este controle possui como objetivo controlar as contas a receber dos clientes e fazer uma previsão de quando o divido valor poderá ser contabilizado no caixa. Segundo Gitman (2010, p.588), "O objetivo da administração das contas a receber é cobrá-las o mais rapidamente possível, sem perder vendas devido a técnicas muito agressivas de cobrança."

E) CONTROLE DE ESTOQUE: Com um organizado controle de estoque o empreendedor pode fornecer informações com mais exatidão sobre as mercadorias possuídas em estoque, facilita na reposição de mercadorias e também possui um controle das mercadorias que estão paradas, Hoji (2008).

Os estoques estão diretamente ligados com o capital de giro, como afirma Hoji (2008). Além disso, o autor afirma que o administrador deve contribuir para que o nível do estoque seja baixo, mas sem prejudicar a atividade da empresa.

F) CAPITAL DE GIRO: São os recursos necessários para financiar as operações dentro do ciclo operacional, estes recursos são necessários para que a empresa possa realizar suas atividades diárias, como por exemplo, o pagamento de obrigação de terceiros, como afirma Hoji (2008).

Para Morante e Fauzi $(2007$, p.41) "administrar o capital de giro pode ser sinônimo de administrar o ativo circulante, composto das disponibilidades, das contas a receber, dos estoques e de outros créditos.".

G) FLUXO DE CAIXA: Segundo Toledo Filho, Oliveira e Spessatto (2011), o fluxo de caixa é a diferença entres as entradas e saídas de caixa. Esta ferramenta auxilia para o controle sobre real situação que a empresa está enfrentando, podendo assim agir imediatamente para ajustar o planejamento e orçamento da empresa.

Para Megliorini e Silva (2009, p.126) "a análise do fluxo de caixa tem como objetivo demonstrar a origem e o destino dos recursos da empresa em determinado período".

Se tratando de microempresa familiar, o fluxo de caixa é uma ferramenta de grande utilidade devido sua facilidade e praticidade na elaboração. (CASTURINO; DAHMER, 2012).

H) FORMAÇÃO DO PREÇO DE VENDAS: Para Hoji (2008), “ a determinação do preço de venda é uma questão fundamental para qualquer empresa. Se ela praticar um preço muito alto inibirá a venda e, se o preço for muito baixo, poderá não gerar o retorno esperado." (HOJI, 2008, p.358). De acordo com o mesmo autor, os preços são impostos pelo mercado, e as empresas precisam se ajustar para acompanhar os concorrentes.

\subsection{Princípio da Entidade}

Segundo o Conselho Federal de Contabilidade- CFC- (2008):

O Princípio da ENTIDADE reconhece o Patrimônio como objeto da Contabilidade e afirma a autonomia patrimonial, a necessidade da diferenciação de um Patrimônio particular no universo dos patrimônios existentes, independentemente de pertencer a uma pessoa, um conjunto de pessoas, uma sociedade ou instituição de qualquer natureza ou finalidade, com ou sem fins lucrativos. Por consequência, nesta acepção, 
o Patrimônio não se confunde com aqueles dos seus sócios ou proprietários, no caso de sociedade ou instituição. Parágrafo único $O$ PATRIMÔNIO pertence à ENTIDADE, mas a recíproca não é verdadeira. A soma ou agregação contábil de patrimônios autônomos não resulta em nova ENTIDADE, mas numa unidade de natureza econômico contábil. (Conselho Federal de Contabilidade, 2008, p.12).

Portanto, o princípio da entidade se refere que o patrimônio da empresa, não pode ser confundido com o patrimônio da família, Abreu, Freitas e Almeida (2012). Segundo ainda os mesmos autores, em uma empresa de médio ou grande porte, a separação dos bens da empresa com os bens da família se dá de uma forma mais clara, porém, em uma microempresa está separação é diferente, pois a gestão se centraliza em uma única pessoa. Para Freire, Lemke, Sousa (2011):

O administrador deverá saber separar os gastos originados pelo negócio (entidade contábil) dos gastos pessoais. E quando houver o caso de administrador utilizar dinheiro da empresa, este terá que contabilizar um empréstimo da entidade para a pessoa física, da mesma forma se o administrador precisar pegar do seu próprio dinheiro para pagar algo da empresa, terá que ser contabilizado empréstimo de pessoa física para a empresa que contraiu o empréstimo. (Freire, Lemke, Sousa, 2011, p.4).

Desse modo, para garantir a estabilidade financeira do empreendimento, o administrador deve separar seu patrimônio pessoal do empresarial. Para assim, ser possível analisar a real saúde financeira da empresa.

\subsection{Temas Relacionados em Trabalhos Acadêmicos}

Dado o objetivo desse trabalho de fazer um diagnóstico da gestão de duas microempresas que atuam no ramo de comércio de alimentos para animais na cidade de Varginha-MG, buscando identificar como são utilizadas as ferramentas de gestão nesses empreendimentos, para assim poder analisar se a utilização das ferramentas de gestão coloca a empresa em uma melhor situação no mercado. Para tanto, foram encontrados trabalhos acadêmicos com temas relacionados, isto é, que tinham por objetivo analisar a gestão das empresas.

Moreira, Ferreira e Costa (2017), verificaram se as empresas do setor de vendas de materiais de construção e ferragens da cidade de Formiga (MG) utilizaram ferramentas financeiras na gestão. De acordo com os autores, todos os gestores demonstraram conhecer as principais ferramentas financeiras, mas as que são mais utilizadas são controle diário de caixa e controle diário de volume de vendas. Além disso, as empresas analisadas têm conhecimento sobre os atrasos dos clientes e possuem políticas para a renegociação de dívidas. As empresas demostraram utilizar somente o relatório financeiro de fluxo de caixa para as análises financeiras. Um ponto de destaque nessa pesquisa foi que os resultados foram contraditórios pelo fato de que as empresas afirmarem fazer uso das ferramentas da administração financeira, porém a maior parte dos administradores consideram a situação financeira e a administração financeira do negócio como boas, porém os resultados financeiros são considerados razoáveis. Esse fato pode indicar que as empresas não estão utilizando as ferramentas financeira de forma eficiente.

O autor Vesco (2000), teve como objetivo verificar quais os instrumentos de gestão econômico-financeiro eram considerados relevantes e utilizados pelas microempresas do 
comércio varejista do vestuário na Associação dos Municípios do Alto Uruguai CatarinenseAMAUC. As empresas entrevistadas são em sua maioria administradas pelos proprietários, que são em grande parte do sexo feminino que possuem o grau de escolaridade até o ensino médio. A informação de gestão mais utilizada é o controle bancário, seguido pelo controle de caixa. A pesquisa informou que os empreendedores, consideram as informações de gestão importantes para a administração do empreendimento. Porém a grande dificuldade encontrada por estes, é não possuírem as informações necessárias para aplicar os conceitos na prática.

As autoras Souza e Rios (2011), tiveram como objetivo fazer uma análise da utilização de algum tipo de ferramenta da Contabilidade Gerencial como gestão financeiras, nas microempresas do município de São Roque- SP. Foram entrevistadas 94 microempresas, e verificou-se que 51,22\% dos empreendedores não utilizam a Contabilidade Gerencial e 28,83\% utilizam.

Santos, Dorow e Beuren (2016), investigaram quais são os instrumentos e procedimentos gerenciais utilizados em micro e pequenas empresas na tomada de decisão. Os resultados mostraram que a tomada de decisão das empresas investigadas é baseada na experiência do proprietário. Além disso, as empresas não recorrem aos contadores para discutir os resultados financeiros obtidos no final do mês.

\section{Metodologia}

A pesquisa é classificada como descritiva, por fazer um diagnóstico da gestão de duas microempresas familiares que atuam no comércio de ração de animais na cidade de Varginha- MG, buscando identificar como estes empreendedores utilizam as ferramentas de gestão no processo de tomada de decisão.

A estratégia de pesquisa utilizada é de levantamento de campo. Segundo Gil (2008) esse tipo de pesquisa tem como característica a interrogação direta das pessoas cujo o comportamento se deseja conhecer.

A presente pesquisa tem como objeto de estudo duas microempresas comerciais no ramo ração de animais, devido à grande expansão do segmento nos últimos anos. Segundo o SEBRAE (2016) uma loja de ração é caracterizada por comercializar alimentos para animais, roupas, brinquedos, perfumes, acessórios, remédios, animais de pequeno porte e uma grande variedade de serviços, como por exemplo, banho e tosa.

O levantamento de dados foi realizado por meio de uma entrevista semiestruturada. A entrevista semiestruturada tem como objetivo básico a coleta de dados. A entrevista foi composta por 40 perguntas para os proprietários de cada empresa, relacionadas com a maneira de gestão que as empresas utilizam.

Foram entrevistados quatro proprietários, dois em cada empresa com objetivo fazer um diagnóstico da gestão das microempresas familiares que atuam no ramo de ração animal na cidade de Varginha, buscando identificar como estes empreendedores utilizam as ferramentas de gestão no processo de tomada de decisão. Para isso foram coletadas informações referentes ao uso das ferramentas financeiras, marketing, posicionamento perante o mercado competitivo e a relação da família com o empreendimento. As duas empresas entrevistadas são familiares, ou seja, a família que administra o próprio negócio. As empresas foram denominadas como empresa "A" e empresa "B". 
A análise dos dados apresenta enfoque qualitativo. Segundo Dalfovo, Lana e Silveira (2008) está análise qualitativa tem o objetivo de verificar a relação da realidade com o objeto de estudo, chegando assim em uma análise indutiva por parte do pesquisador.

\section{Resultado E Discussões}

O presente trabalho teve como objetivo fazer um diagnóstico da gestão de duas microempresas familiares que atuam no comércio de alimentos para animais na cidade de Varginha-MG, buscando identificar como são utilizadas as ferramentas de gestão nesses empreendimentos.

$\mathrm{Na}$ empresa "A", ao questionar os proprietários sobre o nível de conhecimento gerencial que eles possuem, foi respondido que ambos não possuem nenhum conhecimento técnico gerencial, mas ao serem questionados sobre as ferramentas financeiras como o capital de giro e o fluxo de caixa, foi dito que eles possuem um conhecimento superficial sobre as ferramentas.

A empresa faz o levantamento diário de caixa e não possui o controle de vendas diário, porque somente uma pessoa faz as anotações do que foi vendido e os outros não possuem o cuidado de fazer está apuração, que de acordo com Nogueira e Assis (2014), é prejudicial porque, a empresa no final do mês não possui o controle da quantidade de mercadoria vendida e também se a quantidade vendida está de acordo com as metas da empresa.

As contas a pagar são todas registradas, que de acordo com Reinert (2007), este é um controle importante, porque possibilita ao gestor uma melhor visualização das obrigações que ele possui com terceiros. Quanto ao controle das contas a receber, a empresa não determina o dia que o cliente irá pagar a dívida, o que prejudica o capital de giro, uma vez que o dinheiro circulando não será o de terceiros e sim do próprio empreendimento.

O preço da mercadoria é elaborado sobre a margem de $40 \%$ (quarenta por cento) sobre o preço de compra sobre o quilo da ração e $35 \%$ (trinta e cinco por cento) sobre a mercadoria ensacada. A empresa não possui o cuidado de fazer a separação dos custos fixos e dos custos variáveis que tiveram durante o período. Relacionando os dados coletados com Hoji (2008), a empresa na hora de elaborar o preço da mercadoria não leva em consideração os tributos que terá que repassar para o consumidor final, e também como não é feito a apuração dos custos e despesas, a elaboração dos preços feita pela empresa é de forma arbitraria, levando a mesma a não alcançar a margem de lucro desejada, visto que está desconsiderando os tributos, os custos e as despesas.

O estoque não é controlado de forma correta, devido à falta de controle das saídas de mercadorias. A falta de controle de estoque prejudica diretamente o capital de giro da empresa, pelo fato de que representa os ativos financeiros mantidos pela empresa, segundo Hoji (2008).

Embora sobre a opinião do empreendedor a empresa faz o levantamento do fluxo de caixa, ao ser analisado a partir da entrevista realizada, conclui-se que a empresa não possui as informações necessárias para que seja feito a apuração, porque não são apuradas todas as entradas e saídas de caixa. A proprietária resolveu fechar a conta da empresa no banco, porque estava sendo inviável devido à quantidade de capital de terceiros que a empresa estava gerando. As entregas são terceirizadas e é repassado o valor para o cliente. Segundo o proprietário a empresa possui um faturamento de $\mathrm{R} \$ 11.000,00$. Hoje ela possui ao todo oito fornecedores. 
A empresa é a única fonte de renda da família que é composta por cinco membros. Toda a família está de acordo com o propósito do negócio e todos ajudam com o desenvolvimento da empresa. De acordo com os dados coletados na entrevista, o dinheiro em caixa não é respeitado pelos membros da família, porque ocorre muita retirada de dinheiro sem necessidade, que de acordo com Cericato, Amaral e Costa (2013), este desrespeito com o dinheiro em caixa pode levar as empresas a uma necessidade cada vez maior de recorrem a financiamentos para financiar o capital de giro.

Foi elaborado pelos membros da família um plano de contingência, ou seja, uma substituição do responsável do empreendimento caso ocorra algo em que o fundador não possa exercer a função.

A empresa já atua há dez anos no mercado e está localizada em frente a um grande supermercado no bairro Jardim Sion, na cidade de Varginha-MG. De acordo com a entrevista realizada, a empresa se empenha sempre em fazer o melhor para seus clientes e estar sempre conquistando novos. Existe uma preocupação com o cliente sobre satisfação da mercadoria adquirida. Este não é o primeiro empreendimento da família, a mesma já teve uma mercearia que fechou por causa do elevado número de dívidas que tinha para receber.

De acordo com o proprietário, a empresa passou por grandes mudanças desde a sua abertura e eles possuem o objetivo de melhorar ainda mais o negócio.

$\mathrm{Na}$ empresa "B" ao ser questionar os proprietários, verificou-se que esta empresa é mais cuidadosa em relação a coletas de dados relacionados com a gestão, mesmo que somente a filha do casal possua conhecimento técnico na área de gestão. A empresa se preocupa em fazer um rígido levantamento de todas as entradas e saídas de caixa, que de acordo com Assaf Neto e Lima (2009), este levantamento é importante para registrar as origens dos recebimentos e pagamentos e posteriormente na elaboração do fluxo de caixa.

Diariamente todas as mercadorias vendidas são anotadas em uma agenda, as mercadorias vendidas a quilo e as mercadorias ensacadas, e, posteriormente, são passadas para uma planilha no Excel. Este controle segundo Nogueira e Assis (2014), é importante para que o estabelecimento acompanhe se a quantidade vendida está de acordo com a expectativas de vendas esperado pela empresa.

Existe um registro de todas as contas a pagar e a receber, porém o prazo dado pela empresa referente às contas a receber não leva em consideração o tempo dado pelos fornecedores da mercadoria. Não é estipulada uma data para que o cliente pague pela mercadoria, geralmente o pagamento é feito a partir do quinto dia útil. O que é prejudicial para a empresa, porque o dinheiro que irá circular no capital de giro não será o de terceiros, mas sim o da própria empresa.

As entregas são feitas pelo carro da empresa, e somente é cobrada taxa de entrega para os bairros mais distantes. Atualmente a empresa conta com 14 fornecedores, e existe uma preocupação em manter uma boa relação com os fornecedores para conseguirem prazos de pagamento maior e também para contar com os benefícios trazidos dessa boa relação.

A empresa apura todos os custos fixos e todos os custos variáveis que tiveram no período. $\mathrm{O}$ estoque é controlado de uma forma rígida, para que a empresa possa saber quais foram as mercadorias que tiveram maior procura e quais foram as que ficaram paradas em estoque, e isto auxilia o empreendedor na hora de realizar novos investimentos, de acordo Assaf Neto e Lima (2009). 
O preço das mercadorias é elaborado sobre a margem de $35 \%$ (trinta e cinco) sobre o saco de ração e $45 \%$ sobre a ração a quilo. Embora na empresa seja feito o levantamento de todos os custos e despesas do período, na elaboração do preço a proprietária não leva em consideração estes valores e isto é prejudicial devido ao fato que a margem de lucro estipulado pela empresa, acaba não sendo a efetiva que ela vai ganhar, visto que terá deduções dos custos, despesas como afirma Hoji (2008).

Atualmente a empresa fatura $\mathrm{R} \$ 30.000,00$ e o controle do fluxo de caixa é feito uma vez por mês. Geralmente no final do mês a proprietária faz o levantamento de todas as entradas que tiveram no período e de todas as saídas de dinheiro e, assim, chega ao faturamento que a empresa obteve no período.

Foi questionado sobre os conhecimentos sobre o capital de giro e o fluxo de caixa. A proprietária disse que já conhecia o fluxo de caixa, mas não tinha conhecimento sobre o capital de giro. Na opinião da proprietária, a situação financeira da empresa é estável, porque eles possuem capital reservado para caso ocorra algum imprevisto a empresa consiga resolver sem causar grandes danos. A principal dificuldade interna que a empresa encontra é em relação às retiradas de dinheiro do caixa, que é algo que os proprietários se vigiam muito para que não ocorra retiradas desnecessárias.

A empresa é familiar, e a família é composta por três membros, todos trabalham nos estabelecimentos. A empresa é a única fonte de renda da família. De acordo com a proprietária, toda a família respeita o capital da empresa. A família tenta ao máximo não fazer retiradas de caixa desnecessárias, mesmo que eles não possuam salários fixos e os salários são retirados mensalmente do caixa. Como ocorre uma mistura do dinheiro da empresa e o da família, de acordo com Morais (2014), é prejudicial para a empresa, pois estas retiradas podem ocorrer acima da quantidade necessária, afetando diretamente os investimentos, que acarreta na falta de dinheiro para o capital de giro. De acordo com Cericato, Amaral e Costa (2013), o indicado é que a família limite as retiradas em um pró-labore, para que assim não ocorra retiradas em excesso de dinheiro do caixa.

Toda a família está de acordo com o segmento do negócio. Foi elaborado pelos membros da família um plano de contingencia, ou seja, uma substituição do responsável do empreendimento caso ocorra algo em que o fundador não possa exercer a função. Atualmente a empresa possui dois funcionários e uma funcionária que trabalha na casa da família, e todos os salários são pagos pelos ganhos do comércio.

Foi feito um acordo com os fornecedores, para que a empresa divulgasse as novas marcas e consequentemente tivesse uma divulgação do empreendimento, como carros de som, brindes e dias promocionais, mas atualmente a empresa faz divulgações somente pelas redes sociais. A matriz se localiza no bairro Santana, e sua filial Jardim Sion. Na opinião da proprietária as duas localizações são favoráveis. A empresa se preocupa em manter uma relação saudável com seus clientes e se preocupando com a satisfação em relação à mercadoria adquirida.

A empresa está atuando no mercado há 17 anos. A ideia do negócio surgiu devido à existência de um supermercado da família e como muitas pessoas vinham da zona rural para comprarem no supermercado e depois saiam a procura de lojas de ração para comprarem alimentos para os animais, a família resolveu abrir uma pequena loja de ração na garagem de sua casa que ficava ao lado do supermercado. O supermercado fechou alguns anos depois. 
Para conseguir mais clientes e ser um diferencial entre os concorrentes, a empresa optou em colocar o serviço de banho e tosa de animais. Houve grandes evoluções durante o período que a empresa atua no mercado, como a abertura de uma filial. A longo prazo, a empresa pretende montar um consultório veterinário junto com o comercio, devido ao fato que atualmente a filha do casal está cursando graduação de medicina veterinária. Quadro 1:

Para facilitar a visualização das informações apresentadas por cada empresa, segue o

\section{Quadro 1 Síntese comparativa entre as duas empresas}

\begin{tabular}{|c|c|}
\hline \multicolumn{1}{|c|}{ Empresa "A" } & \multicolumn{1}{c|}{ Empresa "B" } \\
\hline $\begin{array}{c}\text { Os proprietários não possuem } \\
\text { conhecimento técnico gerencial; }\end{array}$ & $\begin{array}{l}\text { Somente a filha do casal possui } \\
\text { conhecimento técnico gerencial; }\end{array}$ \\
\hline $\begin{array}{c}\text { A empresa faz o levantamento diário } \\
\text { de caixa, porém não possui o controle de } \\
\text { vendas diário, em consequência não existe } \\
\text { controle de estoque; }\end{array}$ & $\begin{array}{c}\text { A empresa faz um rígido controle das } \\
\text { entradas e saídas de caixa, e se preocupa em } \\
\text { fazer o controle de estoque. }\end{array}$ \\
\hline $\begin{array}{c}\text { As contas a pagar são todas } \\
\text { registradas, mas embora exista um registro } \\
\text { das contas a receber, a empresa não estipula } \\
\text { um dia para o recebimento dos clientes; }\end{array}$ & $\begin{array}{l}\text { As contas a pagar são todas } \\
\text { registradas, mas embora exista um registro } \\
\text { das contas a receber, a empresa não estipula } \\
\text { um dia para o recebimento dos clientes, este } \\
\text { ocorre geralmente no quinto dia útil; }\end{array}$ \\
\hline A empresa é familiar tradicional; & A empresa é familiar tradicional; \\
\hline $\begin{array}{c}\text { A empresa não faz a elaboração do } \\
\text { preço de venda de forma correta; }\end{array}$ & $\begin{array}{c}\text { A empresa não faz a elaboração do } \\
\text { preço de venda de forma correta; }\end{array}$ \\
\hline $\begin{array}{l}\text { A empresa é a única fonte de renda da } \\
\text { família, que é composta por 5 membros, e } \\
\text { todos colaboram para o desenvolvimento e } \\
\text { crescimento da empresa no mercado; }\end{array}$ & $\begin{array}{l}\text { A empresa é a única fonte de renda da } \\
\text { família, que é composta por 3 membros, e } \\
\text { todos colaboram para o desenvolvimento e } \\
\text { crescimento da empresa no mercado; }\end{array}$ \\
\hline $\begin{array}{l}\text { A família não respeita o dinheiro em } \\
\text { caixa da empresa. }\end{array}$ & $\begin{array}{c}\text { A família possui um rígido controle } \\
\text { com o dinheiro de caixa da empresa, porém } \\
\text { não é feito um pró-labore. }\end{array}$ \\
\hline
\end{tabular}

Fonte: Dados da pesquisa. (2018)

Fazendo um comparativo entre as duas empresas, são empresas familiares tradicionais, segundo Lethbrigde (1997), são tradicionais porque a família possui o total controle dos negócios.

Observa-se que a empresa A mesmo sendo lucrativa, enfrenta grandes dificuldades em separar finanças pessoais das finanças empresariais. A família não possui o controle efetivo das saídas de dinheiro de caixa. Isto coloca a empresa em uma situação crítica em relação ao mercado, onde está mistura de dinheiro da família e o dinheiro da empresa pode comprometer a saúde financeira da empresa. Esse resultado se opõem aos resultados encontrados por Moreira, Ferreira e Costa (2017), visto que nas empresas entrevistadas pelos autores todas faziam o controle diário de caixa. Uma justificativa para esse resultado é que neste estudo o objetivo era analisar apenas empresas familiares, onde o princípio contábil da entidade é frequentemente violado, visto que como a administração é focada em apenas uma pessoa ou em poucas, fica a 
critério a tomada de decisões do empreendimento, conforme já apresentado por Freire, Lemke, Sousa (2011).

Outro fato que chama a atenção na análise dos dados, é em relação à falta de conhecimento de ambos empreendedores em montarem o preço de venda das mercadorias. Além disto, ambas as empresas não estipulam o tempo exato que os clientes devem pagar suas dívidas, dificultando assim a administração do capital de giro, uma vez que o dinheiro que irá circular vai ser o da empresa e não o de terceiros. Esse resultado se opõem aos resultados encontrados na academia (Moreira, Ferreira e Costa (2017), Vesco (2000), Souza e Rios (2011)), visto que sem a previsão para a entrada de inadimplências a empresa não terá informações suficientes para montar seu fluxo de caixa e demais ferramentas de controle financeiro.

Ambas as empresas não possuem o controle de retorno sobre os investimentos realizados, ou seja, ao serem questionadas sobre quantas mercadorias eram necessárias serem vendidas para a recuperação do investimento realizado, os dois empreendedores não souberam informar devido à falta de controle interno. De acordo com Morante e Fauzi (2007) esta falta de controle é prejudicial, devido à falta de informação para a gestão, sobre se o dinheiro que está circulando no capital de giro é o retorno do investimento realizado ou se o dinheiro é do empreendimento.

Outro ponto que merece destaque nos resultados é a centralização do processo de tomada de decisões em apenas uma pessoa, geralmente o dono ou em poucos membros da família, desse modo a tomada de decisão é baseada na experiência do dono do estabelecimento. Esse resultado vai de encontro com os achados de Santos, Dorow e Beuren (2016).

A empresa $\mathrm{B}$ se mostrou mais organizada em relação às ferramentas financeiras, e isto leva a empresa a alcançar melhores resultados no mercado, como a abertura de uma filial.

Em comparação com os trabalhos relacionados, conclui-se que as ferramentas de gestão, ainda são desconhecidas por grande parte dos empreendedores. E quando os empresários utilizam essas ferramentas, eles conseguem mais estabilidade financeira em seu negócio (Moreira, Ferreira e Costa (2017), Santos, Dorow e Beuren (2016), Vesco (2000), Souza e Rios (2011)).

\section{Considerações Finais}

Tendo em vista o objetivo central deste trabalho, de fazer um diagnóstico da gestão de duas microempresas familiares que atuam no ramo comércio de alimentos para animais na cidade de Varginha- MG, foi possível constatar que a utilização de ferramentas de gestão auxilia o empreendedor na tomada de decisões e foi possível verificar que o empreendimento que utiliza esta ferramenta consegue manter a situação financeira da empresa mais estável.

Com este estudo foi possível verificar que existem muitos pontos positivos que contribuem para o crescimento de ambas as empresas. Além disso, destacou-se alguns pontos negativos que precisam ser solucionados para garantir uma boa gestão e crescimento futuro para a empresa.

Pode-se ressaltar como ponto negativo para a empresa A, a falta de controle das retiradas de dinheiro do caixa da empresa. Isto é prejudicial devido ao fato que descontrola todas as 
obrigações que a empresa possui e também dificulta, no final do mês, em saber qual foi o real lucro obtido pela empresa.

Outro ponto negativo que foi identificado, foi o despreparo dos empreendedores em elaborar o preço da mercadoria vendida, que é uma tarefa importante, pois contribuirá diretamente com o lucro líquido da empresa.

A localização de ambas as empresas é favorável para os empreendimentos, visto que se localizam em avenidas movimentadas da cidade. E se tratando de serem ambas as empresas familiares, a tomada de decisões e a implantação de novos objetivos ocorrem de forma mais rápida.

Em resumo, ambas as empresas entrevistadas são familiares, todos os membros da família auxiliam nas atividades empresarias. De acordo com os dados da pesquisa, a empresa "B" possui uma gestão mais controlada, em comparação com a outra empresa, pois todas as entradas e saídas de caixa são controlados. Já a empresa "A" não faz a aplicação do princípio da entidade, ou seja, o patrimônio da empresa se mistura com o pessoal, o que é prejudicial para a gestão da empresa, pois seus proprietários não terão o conhecimento da rentabilidade de seu negócio.

A partir dos resultados apresentado nesse trabalho, sugere-se que as empresas comecem a coletar todas as informações necessárias para o preenchimento dos formulários financeiros para que seja possível acompanhar a real situação da saúde financeira de seus empreendimentos. Além disso, aos empreendedores buscarem ajuda aos contadores para discutirem e projetarem metas e melhorias para a gestão dos empreendimentos.

Com as informações apresentadas, conclui-se que a utilização de ferramentas para avaliar a gestão da empresa auxilia o gestor na tomada de decisões e no desenvolvimento da empresa no mercado competitivo em que se encontram, porém, muitas ferramentas de gestão ainda são desconhecidas pelos empreendedores. Além disso, se tratando de empresas familiares a falta de organização entre empresa e família acaba levando as empresas estarem em situações críticas diante do mercado.

Portanto, o objetivo geral do artigo foi atingido, porém ainda ficará um interesse de estudar futuramente, mais segmentos comerciais na cidade de Varginha-MG, para assim poder verificar de que forma é feita gestão das empresas, principalmente das empresas familiares.

\section{Referências Bibliográficas}

ABREU, Elcilene de Ester; FREITAS, Lucieni Bello de; ALMEIDA, Fernanda Matos de Moura. Aplicabilidade do Princípio Contábil da Entidade Aos Supermercados Localizados no Município de Irupi-es. In: $9^{\circ}$ Simposio de Excelencia em Gestão e Tecnologia. Espírito Santo. 2012.

ASSAF NETO, Alexandre; LIMA, Fabiano Guasti. Curso de administração financeira- São Paulo: Atlas, 2009.

BRASIL, 2016. Lei Complementar 155, de 27 de outubro de 2016. Institui o Estatuto Nacional da Microempresa e da Empresa de Pequeno Porte. Diário Oficial da União. Brasília, 27 out. 2016. 
CASTURINO, VANDERSEZAR; DAHMER, LAERCIO. Fluxo de Caixa como Ferramenta de Gestão Financeira para Microempresas. Contabilidade \& Amazônia, v. 1, n. 1, p. 1-7, 2012.

CERICATO, Domingo; AMARAL, José Juparitã do; COSTA, Alexandre Marino. CARACTERÍSTICAS DO FINANCIAMENTO DE CAPITAL DE GIRO: ESTUDODIRIGIDO ÀS MICRO EMPRESAS DO COMÉRCIO DE PASSO FUNDO (RS). Revista de Administração, v. 3, n. 4, p. p. 117-136, 2013.

CINTRA, Marcos Antônio Macedo; FARHI, Maryse. A crise financeira e o global shadow banking system. Novos estudos-CEBRAP, n. 82, p. 35-55, 2008.

CONSELHO FEDERAL DE CONTABILIDADE. Princípios fundamentais e normas brasileiras de contabilidade. 3. ed. Brasília: CFC, 2008. 404 p.

DALFOVO, Michael Samir; LANA, Rogério Adilson; SILVEIRA, Amélia. Métodos quantitativos e qualitativos: um resgate teórico. Revista Interdisciplinar Científica Aplicada, v. 2, n. 3, p. 1-13, 2008.

DONATTI, Lívia. Empresa familiar: a empresa familiar em um âmbito global. Caderno de pesquisas em administração, v. 1, n. 10, 1999.

EMPRESOMÊTRO. Disponível em: < http://empresometro.cnc.org.br/> Acesso em: 15 mai. De 2017.

FREIRE,.Jozielton dos Reis; LEMKE, Valdinéia; SOUZA, Almir da Cruz. Mistura das contas pessoais patrimoniais em micro e pequenas empresas: estudos múltiplos de casos no setor supermercadista de Santa Teresa. VIII Convibra Administração - Congresso Virtual Brasileiro de Administração. 2011. ES. p. 1 a p.14.

GIL, Antônio Carlos. Métodos e técnicas de pesquisa social. - 6. ed.- São Paulo: Atlas, 2008.

GITMAN, Lawrence J. Princípios da administração financeira; tradução Allan Vidigal Hastings; revisão técnica Jean Jacques Salim. - 12. ed.- São Paulo: Pearson Prentice Hall, 2010.

GONÇALVES, J. S. R. C. As empresas familiares no Brasil. Revista de Administração de empresas, v. 40, n. 1, p. 7-12, 2000.

HOJI, Masakazu. Administração Financeira e Orçamentária: matemática financeira aplicada, estratégias financeiras, orçamento empresarial. $7^{\circ}$. ed. São Paulo: Atlas S.A, 2008.

INÁCIO, Sandra Regina da Luz. Manual de Perguntas e Respostas Sobre Empresas Familiares - Tudo o que você sempre desejou saber sobre as Empresas Familiares. 2005. 
Disponível em: < http://www.crasp.gov.br/crasp/conteudo/livro.pdf > Acesso em: 19 de maio de 2016.

LETHBRIDGE, Eric. Tendências da empresa familiar no mundo. Revista do BNDES, v. 7, n. $1,1997$.

MANKIW, N. Gregory. Introdução à economia. Tradução Allan Vidigal Hastings, Elisete Paes e Lima- $6^{\circ}$ ed.- São Paulo: Cengage Learning, 2014.

MEGLIORINI, Evandir; SILVA, Marco Aurélio Vallim Reis da. Administração financeira: uma abordagem brasileira. São Paulo: Pearson Prentice Hall, 2009.

MORAIS, Ana Paula Araújo Bezerra de. Mistura de contas pessoais e empresariais em uma microempresa do Setor Calçadista na Cidade de Patos. 2014. 26 f. TCC (Graduação) Curso de Administração, Universidade Estadual da Paraíba- Centro de Ciências Sociais e Aplicadas, Patos, 2014.

MORANTE, Antônio Salvador; FAUZI, Timaco Jorge. Administração financeira: decisões de curto prazo, decisões de longo prazo, indicadores de desempenho. - São Paulo: Atlas: 2007.

MOREIRA, Bruno César Melo; FERREIRA, Natália Aparecida Gondim; COSTA, Daniel Fonseca. Avaliação do uso de Ferramentas Financeiras na Prática de Gestão das Empresas do Setor de Vendas de Material de Construção e Ferragens. Revista de Gestão e Contabilidade da UFPI, v. 4, n. 1, p. 105-128, 2016.

NOGUEIRA, Leandro Rivelli Teixeira; ASSIS, Jonatas Martins. GESTÃO FINANCEIRA DE PEQUENOS NEGÓCIOS-APOIO AO MERCADO DOS BAIRROS DO JARDIM SION E SANTANA-VARGINHA/MG. Revista Extendere, v. 1, n. 2, 2014.

OLIVEIRA, Pinho Rebouças Djalma. Empresa Familiar. São Paulo: Editora Atlas, 1999.

REINERT, Nilséia. A Necessidade de Organização dos Controles Financeiros para uma Melhor Gestão de Empresas de Pequeno Porte. VI seminário do Centro de Ciências Sociais Aplicadas de Cascavél. 2007;

SANTOS, Vanderlei dos; DOROW, Diego Roberto; BEUREN, Ilse Maria. Práticas gerenciais de micro e pequenas empresas. REVISTA AMBIENTE CONTÁBIL-Universidade Federal do Rio Grande do Norte-ISSN 2176-9036, v. 8, n. 1, p. 153-186, 2016.

SEBRAE - Serviço Brasileiro de Apoio às Micro e Pequenas Empresas- Como montar uma loja de animais ou pet shop. Site disponível em: < http://www.sebrae.com.br/sites/PortalSebrae/ideias/como-montar-uma-loja-de-animais-oupet-shop,88187a51b9105410VgnVCM1000003b74010aRCRD\#naveCapituloTopo > Acesso em: 17 de abril de 2016. 
SEBRAE - Serviço Brasileiro de Apoio às Micro e Pequenas Empresas- Pesquisa sobre micro e pequenas empresas paulistas. Site disponível em: < http://www.sebraesp.com.br/index.php/234-uncategorised/institucional/pesquisas-sobremicro-e-pequenas-empresas-paulistas/micro-e-pequenas-empresas-em-numeros> Acesso em: 08 de junho de 2016.

SILVA, Jonathan A. Degrandi; DOS SANTOS, Heloisa Corrêa; DA SILVA, Ademir. A IMPORTÂNCIA DA GESTÃO DE CUSTOS COMO DIFERENCIAL PARA MICRO E PEQUENAS EMPRESAS. Revista Eletrônica Organizações e Sociedade, v. 5, n. 4, p. 7992, 2017.

SOUZA, RAR de; RIOS, Ricardo Pereira. Contabilidade gerencial como ferramenta para gestão financeira nas microempresas: uma pesquisa no município de São Roque SP. Revista Eletrônica Gestão e Negócios, v. 2, n. 1, p. 1-18, 2011.

TOLEDO FILHO, Jorge Ribeiro de; OLIVEIRA, Everaldo Leonel de; SPESSATTO, Giseli. Fluxo de Caixa como Instrumento de Controle Gerencial para Tomada de Decisão: um estudo realizado em microempresas. Revista de Contabilidade do Mestrado em Ciências Contábeis da UERJ, v. 15, n. 2, p. 75-88, 2011.

VESCO, Ari dal. Um estudo dos instrumentos de informação econômico-financeira utilizados no processo de gestão das microempresas do comércio varejista da associação dos munícipios do Alto Uruguai Catarinense- AMAUC. 2000. 167 f. Dissertação (Mestrado) - Curso de Administração, Universidade Federal de Santa Catarina, Florianópolis, 2000. 